\title{
Medical management of irritable bowel syndrome in 2008: Current and future directions
}

\author{
Martin Storr MD, Christopher N Andrews MD MSc FRCPC
}

$\mathrm{I}_{\mathrm{man}}^{\mathrm{m}}$ rritable bowel syndrome (IBS) is a challenge for physicians and researchers. Our present understanding of IBS pathophysiology includes altered environmental factors, changes in genetics, postinflammatory circumstances, small bacterial overgrowth, food intolerances and alterations in serotonin signalling.

The overall goal in treating IBS patients is to provide relief of symptoms and improve the well-being of the patients. The first important task is to educate and explain the nature of the disease to the patient, and reassure them about the chronic but ultimately benign nature of the disorder.

\section{CURRENT PHARMACOLOGICAL THERAPY}

For the gastroenterologist, pharmacological therapy is the cornerstone of IBS management. Therapy is symptom-based, with agents targeted at the most bothersome symptoms. Constipation is treated with laxatives or stool softeners. Antispasmodics and antidiarrheals are used in patients with diarrhea and abdominal cramping. Depending on their site of action, they act as musculotropics or neurotropics. The alkaloids, papaverine and mebeverine, and the calcium channel antagonist, pinaverium (Dicetel, Solvay Pharma Inc, Canada), are musculotropics that reduce the ability of the gut smooth muscle to contract and, therefore, reduce colonic motility and spasm activity. Atropine works via inhibition of cholinergic nerves to achieve the same result, but is rarely used. Other neurotropics, such as butylscopolamine (Buscopan, Boehringer Ingelheim Ltd, Canada), dicyclomine (Bentylol, Axcan Pharma Inc, Canada; and Formulex, Valeant Canada Ltd, Canada) and hyoscyamine (Cystospaz, Amerifit Nutrition Inc, USA; and Levsin, Schwarz Pharma Kremers Urban Company, USA), act similarly to atropine and can be found in multiple formulations. In addition, the spasmolytic, trimebutine (Modulon, Axcan Pharma Inc, Canada), appears to act on multiple sites. A recent Cochrane analysis (1) suggests that for IBS patients treated with antispasmodics, the number needed to treat is six.

Low-dose tricyclic antidepressants such as amitriptyline (Elavil, 1560678 Ontario Inc, Canada), desipramine (Norpramin, Sanofi-Aventis US LLC, USA) and imipramine (Tofranil, Novartis Pharmaceuticals Canada Inc, Canada); and selective serotonin reuptake inhibitors, such as fluoxetine (Prozac, Eli Lilly Canada Inc, Canada; and Sarafem, Eli Lilly and Company, USA) and citalopram (Celexa, Lundbeck
Canada Inc, Canada), are effective in treating the pain, discomfort and bloating aspects of IBS (2). By altering serotonin function in the central and peripheral nervous systems, they reduce pain in patients with IBS and are used at doses below those used for psychiatric indications such as depression. Clinical trials show a large variability in the response; however, they are a good option in pain-predominant patients, especially if they have comorbid psychiatric conditions and a lack of response to other therapies $(2,3)$.

Due to cardiovascular events, the 5-hydroxytryptamime receptor $4\left(5-\mathrm{HT}_{4}\right)$ agonist, tegaserod (Zelnorm, Novartis Pharmaceuticals Corporation, USA), was withdrawn from the Canadian and United States markets on March 30, 2007, with no plans for special or compassionate release in Canada as of the time of the present review. Alosetron (Lotronex, Prometheus Laboratories Inc, USA), a 5-hydroxytryptamine $3\left(5-\mathrm{HT}_{3}\right)$ receptor antagonist has limited availability in the United States and is not available in Canada.

Phytotherapy is often used in IBS patients. Despite the fact that numerous preparations are available, only the phytotherapeutic agent STW5 (Iberogast, Steigerwald GmbH, Germany), which has been available in Canada since 2007, is supported by double-blind, randomized, placebo-controlled data (4). Growing interest in probiotics (Florastor, Biocodex Inc, France; VSL\#3, VSL Pharmaceuticals Inc, USA; and TuZen, Ferring Inc, Canada) has also given rise to a small number of trials suggesting benefit in IBS, but larger trials are needed to recommend them for pharmacological use (5).

\section{NEW STUDIES WITH AVAILABLE MEDICATIONS AND APPROACHES}

2007 was a good year for research on future treatments of IBS. Numerous clinical publications of research on IBS patients were published in MEDLINE or reported at Digestive Disease Week 2007, and have the power to influence clinical practice immediately or in the near future.

Pregabalin (Lyrica; Pfizer Canada Inc, Canada) is an $\alpha_{2} \delta$ receptor ligand that was recently approved for the treatment of neuropathic pain. In animal studies, pregabalin was found to reduce visceral allodynia and hyperalgesia. Now, a randomized, double-blind, placebo-controlled study (6) on 26 patients with IBS and hypersensitivity to rectal distention showed that pregabalin increased rectal sensory thresholds to normal values and increased rectal compliance, the latter

Division of Gastroenterology, University of Calgary, Calgary, Alberta

Correspondence: Dr Martin M Storr, Division of Gastroenterology, University of Calgary Medical Clinic, 3330 Hospital Drive Northwest,

Calgary, Alberta T2N 4N1. Telephone 403-592-5034, fax 403-592-5090, e-mail mstorr@ucalgary.ca

Received for publication March 4, 2008 
effect being unrelated to changes in sensitivity. These promising data now need to be addressed in a clinical trial on patients with IBS.

A pilot study (7) in 18 IBS patients found that eight weeks of treatment with oral melatonin significantly reduced IBS symptom scores. Whether this effect holds true in larger controlled trials and whether melatonin, which is known to affect motility, is effective in normalizing bowel habits in IBS patient subtypes needs to be addressed in future trials.

The results of another pilot study (8) on the opioid antagonist, naltrexone (ReVia; Duramed Pharmaceuticals Inc, USA), performed as an open-label study in 42 patients with IBS, suggested that naltrexone improves pain and overall feeling, but these promising data have to be verified in larger, controlled clinical trials.

An abstract (9) focused on probiotic yogurt (Lactobacillus paracasei, Lactobacillus acidophilus and Bifidobacterium lactis) and reported improved overall symptom severity in 118 IBS patients, but this randomized study showed that the beneficial effects were not superior to the control group, which received acidified milk without the probiotic bacteria. In contrast, another abstract (10) focused on the probiotic, Escherichia coli, which was proven in a double-blind, placebo-controlled, randomized, multicentre trial in 297 IBS patients to be superior in relieving patients' symptoms when given 20 drops orally, three times per day. The beneficial effect of $E$ coli was stressed by a retrospective trial (11) performed in private practice, where stool frequency and other symptoms, such as urge, flatulence and abdominal fullness, were improved in a large number of patients with diarrhea-predominant IBS (D-IBS). A randomized, doubleblind, placebo-controlled trial (12) including 37 children with IBS showed that Lactobacillus GG treatment reduced the frequency, but not the severity, of abdominal pain. Whether all these differences in effectiveness of probiotics are due to the different bacteria provided, the different matrix by which they are delivered or the different regimen of application needs to be addressed in future trials, to clarify the merit of these treatments.

A randomized, controlled trial (13) in pediatric patients with IBS proved that hypnotherapy is superior to standard medical therapy (SMT) in relieving pain associated with IBS. This effectiveness was observable for pain intensity and pain frequency, whereas other IBS-related symptoms were not better relieved with hypnotherapy than with SMT. SMT consisted of education, dietary intervention and intervention on stress factors. Psychological interventions are also helpful in adults, and a randomized study (14) of 147 patients with IBS showed that cognitive behaviour therapy has direct effects on symptom improvement independent of its effects on distress. These trials once again point to the importance of psychological interventions in IBS patients, which should be accessible to all patients.

\section{DRUGS IN THE PIPELINE}

Lubiprostone is a locally acting type-2 chloride channel activator that induces intestinal fluid secretion. Efficacy of this treatment in patients with chronic constipation has been shown in recent trials. A new trial (15) presented data on a 12-week multicentre, randomized, double-blind, placebo-controlled phase III study. The trial included 1167 patients with constipationpredominant IBS (C-IBS), diagnosed using the Rome II criteria. A large proportion of the trial population were women $(91.6 \%)$. In this trial, oral lubiprostone was superior to placebo in relieving abdominal pain and constipation, and increased stool frequency and quality of life. Nausea and diarrhea were the most common adverse effects, and occurred more often than in the treatment group. Lubiprostone is currently approved in the US, and late-stage trials are underway in Canada.

A retrospective analysis (16) suggested that the antibiotic, rifaximin, is superior to other antibiotics in achieving clinical response and this is additionally stressed by pre- and posttreatment breath test analysis. This agent is very poorly absorbed when taken orally and, therefore, is well suited for luminal gut use in bacterial overgrowth situations. It is available in the United States but not in Canada at the present time.

Linaclotide is a novel agonist of human guanylate cyclase-C. Guanylate cyclase-C activation induces fluid secretion in the small intestine and fluid absorption in the large intestine. From phase I studies, linaclotide was known to decrease stool consistency, and increase stool frequency and ease of stool passage in healthy volunteers while being well tolerated. Now, oral linaclotide was shown in a randomized, double-blind, placebocontrolled trial (17) in 36 women with C-IBS to improve stool consistency, frequency and ease of passage in a dose-dependent manner over five days. These promising data now await verification in larger, long-term trials. The efficacy of linaclotide in male patients with C-IBS awaits investigation.

Crofelemer is a component of the extract of the plant Croton lechleri, which is used in South America for symptomatic treatment of diarrhea. A randomized, double-blind, placebo-controlled trial (18) in 246 patients with D-IBS proved that oral crofelemer improved pain, whereas trends for improved stool consistency and reduced stool frequency were not statistically significant.

Dextofisopam is a nonsedating agent with a benzodiazepine ring that binds to a novel binding site within the central nervous system, and is distinct from the classic benzodiazepine receptor. A recent double-blind, placebocontrolled trial (19) of 140 patients with D-IBS or alternating IBS showed that dextofisopam improved overall symptom score in all patients, stool consistency in both male and female patients with D-IBS and stool frequency in female D-IBS patients. Interestingly, the beneficial effect vanished over time. Future studies should be performed to clarify whether this drug can be used in IBS patients in the future.

Pumosetrag is a novel partial $5-\mathrm{HT}_{3}$ agonist and, in 2007, data from a phase IIa trial (20) performed on 91 patients with C-IBS showed superiority over placebo treatment. However, detailed publication of the study is not yet available.

The $5-\mathrm{HT}_{3}$ antagonist, alosetron, which was withdrawn in 2000 due to increased incidence of ischemic colitis, was reintroduced for restricted use in 2002. As mentioned above, this medication has never been approved in Canada. In a randomized, double-blind, placebo-controlled trial (21) including 705 female patients with D-IBS, alosetron proved to be superior to placebo in relieving overall pain and discomfort after 12 weeks. This effect was seen with all three tested doses of alosetron.

\section{RECENT NEGATIVE STUDIES}

Whereas positive data were presented for some drugs, other drugs failed to be effective.

A randomized, double-blind, placebo-controlled 12-week treatment trial (2) compared imipramine, citalopram and placebo treatment in 51 IBS patients. This trial did not report differences between citalopram and imipramine, or significantly improved IBS end points over placebo but, given the short 
duration of the trial and the small patient population, the study has to be seen as a pilot trial.

Talnetant (SB223242), a neurokinin-3 ( $\left.\mathrm{NK}_{3}\right)$ receptor antagonist, failed in two clinical trials. One included 618 patients of all IBS subtypes and the other included 732 patients with non-D-, non-C-IBS. Although data from basic research suggest a reduction in visceromotor responses to painful stimuli, translation into patients with IBS was not successful (22).

The peripheral, active kappa-opioid agonist, asimadoline, was tested in a placebo-controlled, double-blind trial including 100 IBS patients. Asimadoline was taken on-demand during abdominal pain episodes but failed to be effective in this setting. Additionally, post hoc analysis showed that symptoms were worsened in D-IBS patients (23). Further studies must establish whether asimadoline is beneficial in IBS patients under other treatment schedules.

\section{CONCLUSIONS}

Present therapies for IBS effectively treat single symptoms, but their use may be limited when patients have moderate-to-severe symptoms or when they present with multiple symptoms. The multisymptom nature of IBS might reflect the need for multiple treatment modalities, comparable with the treatment of patients with coronary artery disease. Future treatment of IBS may see a multitarget approach in which motility, pain and psychiatric comorbidities are treated at the same time with different therapies.

Numerous alternative and complementary therapies are used for symptomatic IBS treatment but randomized, placebocontrolled studies for this approach are missing. Along with pharmacological therapies, additional measures should be part of the approach toward the patient, at least for the patients with moderate-to-severe symptoms. These additional measures include behavioural therapies like cognitive therapy, relaxation training, biofeedback or hypnosis.

IBS is a major burden to both patients and society. Presently, treatment options seem to be limited. However, over the past year, numerous published clinical trials have shown that interest in this field is growing and promising drugs are being tested. Some of them might be available for clinical use in the near future. This is good news for patients suffering from IBS.

\section{REFERENCES}

1. Quartero AO, Meineche-Schmidt V, Muris J, Rubin G, de Wit N. Bulking agents, antispasmodic and antidepressant medication for the treatment of irritable bowel syndrome. Cochrane Database Syst Rev 2005;CD003460.

2. Talley NJ, Kellow JE, Boyce P, Tennant C, Huskic S, Jones M. Antidepressant therapy (imipramine and citalopram) for irritable bowel syndrome: A double-blind, randomized, placebo-controlled trial. Dig Dis Sci 2007;53:108-15.

3. Foxx-Orenstein A. IBS - review and what's new. MedGenMed 2006;8:20.

4. Madisch A, Holtmann G, Plein K, Hotz J. Treatment of irritable bowel syndrome with herbal preparations: Results of a double-blind, randomized, placebo-controlled, multi-centre trial. Aliment Pharmacol Ther 2004;19:271-9.

5. Camilleri M. Probiotics and irritable bowel syndrome: Rationale, putative mechanisms, and evidence of clinical efficacy. J Clin Gastroenterol 2006;40:264-9.

6. Houghton LA, Fell C, Whorwell PJ, Jones I, Sudworth DP, Gale JD. Effect of a second-generation alpha2delta ligand (pregabalin) on visceral sensation in hypersensitive patients with irritable bowel syndrome. Gut 2007;56:1218-25.

7. Saha L, Malhotra S, Rana S, Bhasin D, Pandhi P. A preliminary study of melatonin in irritable bowel syndrome. J Clin Gastroenterol 2007;41:29-32.

8. Kariv R, Tiomny E, Grenshpon R, et al. Low-dose naltreoxone for the treatment of irritable bowel syndrome: A pilot study. Dig Dis Sci 2006;51:2128-33.

9. Simren M, Lindh A, Samuelsson L, et al. Effect of yoghurt containing three probiotic bacteria in patients with irritable bowel syndrome (IBS) - a randomized, double-blind, controlled trial. Gastroenterology 2007;132(4 Suppl 2):A210. (Abst)

10. Enck P, Mencke G, Zimmerman K, Martens U, Klosterhalfen S. Effective probiotic therapy of the irritable bowel syndrome (IBS): A multi-center clinical trial with primary care physicians. Gastroenterology 2007;132(4 Suppl 2):A79. (Abst)

11. Plassmann D, Schulte-Witte H. [Treatment of irritable bowel syndrome with Escherichia coli strain Nissle 1917 (EcN): A retrospective survey.] Med Klin (Munich) 2007;102:888-92.

12. Gawronska A, Dziechciarz P, Horvath A, Szajewska H. A randomized double-blind placebo-controlled trial of Lactobacillus GG for abdominal pain disorders in children. Aliment Pharmacol Ther 2007;25:177-84.

13. Vlieger AM, Menko-Frankenhuis C, Wolfkamp SC, Tromp E, Benninga MA. Hypnotherapy for children with functional abdominal pain or irritable bowel syndrome: A randomized controlled trial. Gastroenterology 2007;133:1430-6.

14. Lackner JM, Jaccard J, Krasner SS, Katz LA, Gudleski GD, Blanchard EB. How does cognitive behavior therapy for irritable bowel syndrome work? A mediational analysis of a randomized clinical trial. Gastroenterology 2007;133:433-44.

15. Lembo AJ, Rosenbaum DP, Chey WD, Drossman DA. Safety and efficacy of crofelemer in patients with diarrhoea predominant irritable bowel syndrome (d-IBS). Gastroenterology 2007;132(4 Suppl 2):A141. (Abst)

16. Yang J, Lee HR, Low K, Chatterjee S, Pimentel M. Rifaximin versus other antibiotics in the primary treatment and retreatment of bacterial overgrowth in IBS. Dig Dis Sci 2008;53:169-74.

17. Andresen V, Camilleri M, Busciglio IA, et al. Effect of 5 days linaclotide on transit and bowel function in females with constipation-predominant irritable bowel syndrome. Gastroenterology 2007;133:761-8.

18. Drossman DA, Chey W, Panas R, Wahle A, Scott C, Ueno R. Lubiprostone significantly improves symptom relief rates in adults with irritable bowel syndrome and constipation (IBS-C): Data from two, twelve-week, randomized, placebo-controlled, double-blind trials. Gastroenterology 2007;132(4 Suppl 2):A191. (Abst)

19. Leventer SM, Raudibaugh K, Frissora CL, et al. Clinical trial: Dextofisopam in the treatment of patients with diarrhoeapredominant or alternating irritable bowel syndrome. Aliment Pharmacol Ther 2008;27:197-206.

20. Evangelista S. Drug evaluation: Pumosetrag for the treatment of irritable bowel syndrome and gastroesophageal reflux disease. Curr Opin Investig Drugs 2007;8:416-22.

21. Krause R, Ameen V, Gordon SH, et al. A randomized, double-blind, placebo-controlled study to assess efficacy and safety of $0.5 \mathrm{mg}$ and $1 \mathrm{mg}$ alosetron in women with severe diarrhea-predominant IBS. Am J Gastroenterol 2007;102:1709-19.

22. Dukes GE, Dewit OE, Sanger GJ, et al. Lack of effect of the NK3 receptor antagonist, Talnetant SB223242 on symptoms of IBS: Results of two randomized, double-blind, placebo-controlled dose ranging trials. Gastroenterology 2007;132(4 Suppl 2):A60. (Abst)

23. Szarka LA, Camilleri M, Burton D, et al. Efficacy of on-demand asimadoline, a peripheral kappa-opioid agonist, in females with irritable bowel syndrome. Clin Gastroenterol Hepatol 2007;5:1268-75. 


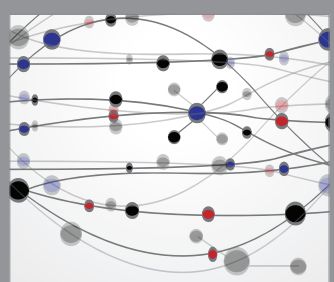

The Scientific World Journal
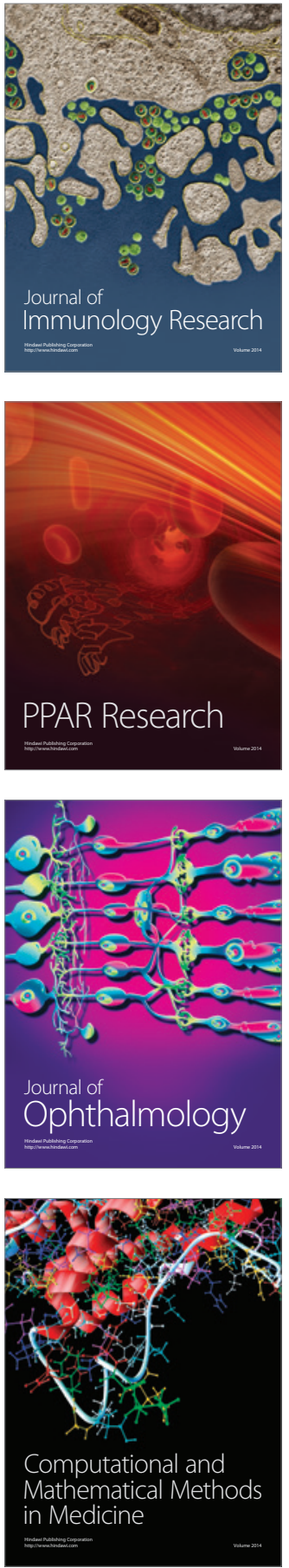

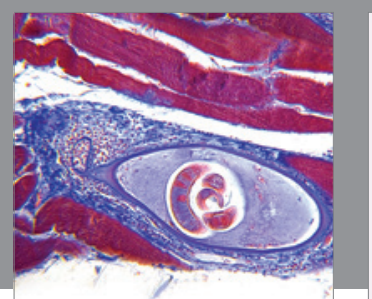

Gastroenterology Research and Practice

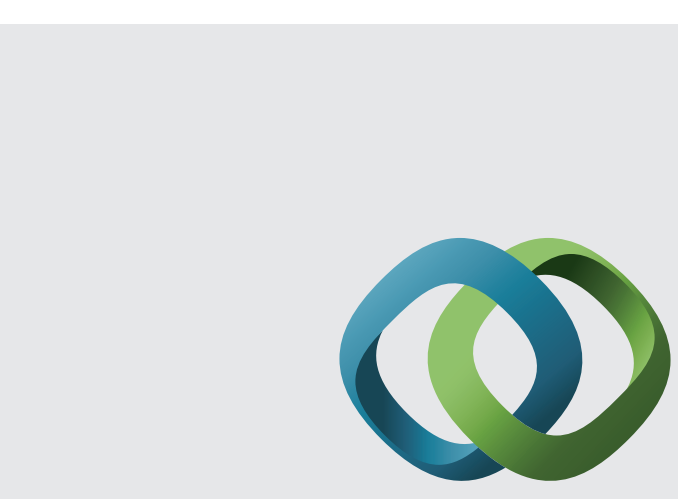

\section{Hindawi}

Submit your manuscripts at

http://www.hindawi.com
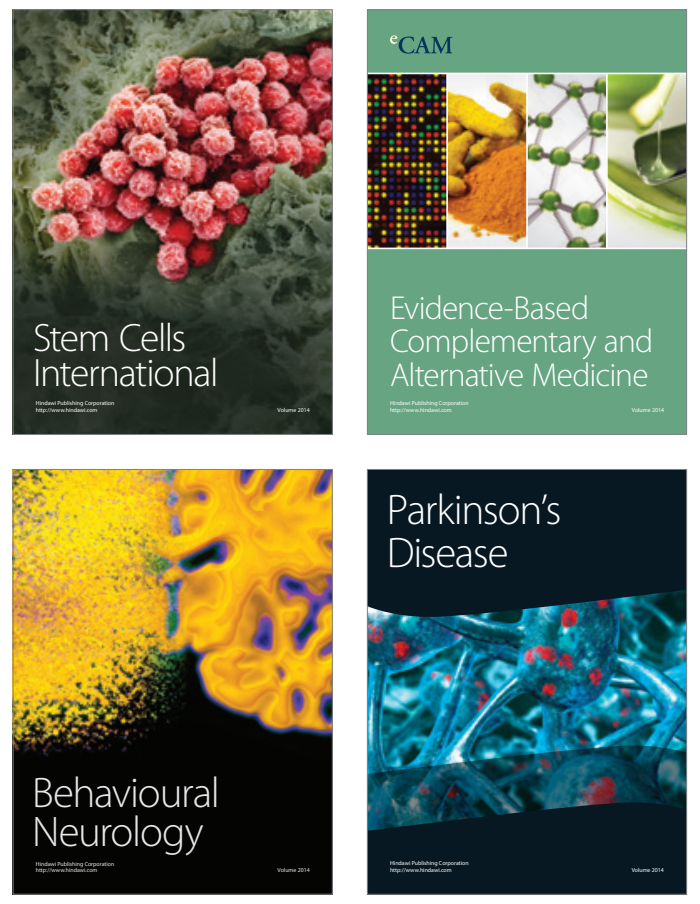
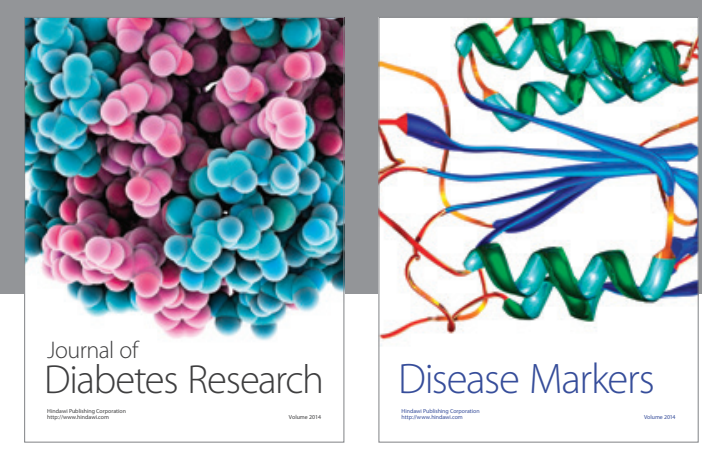

Disease Markers
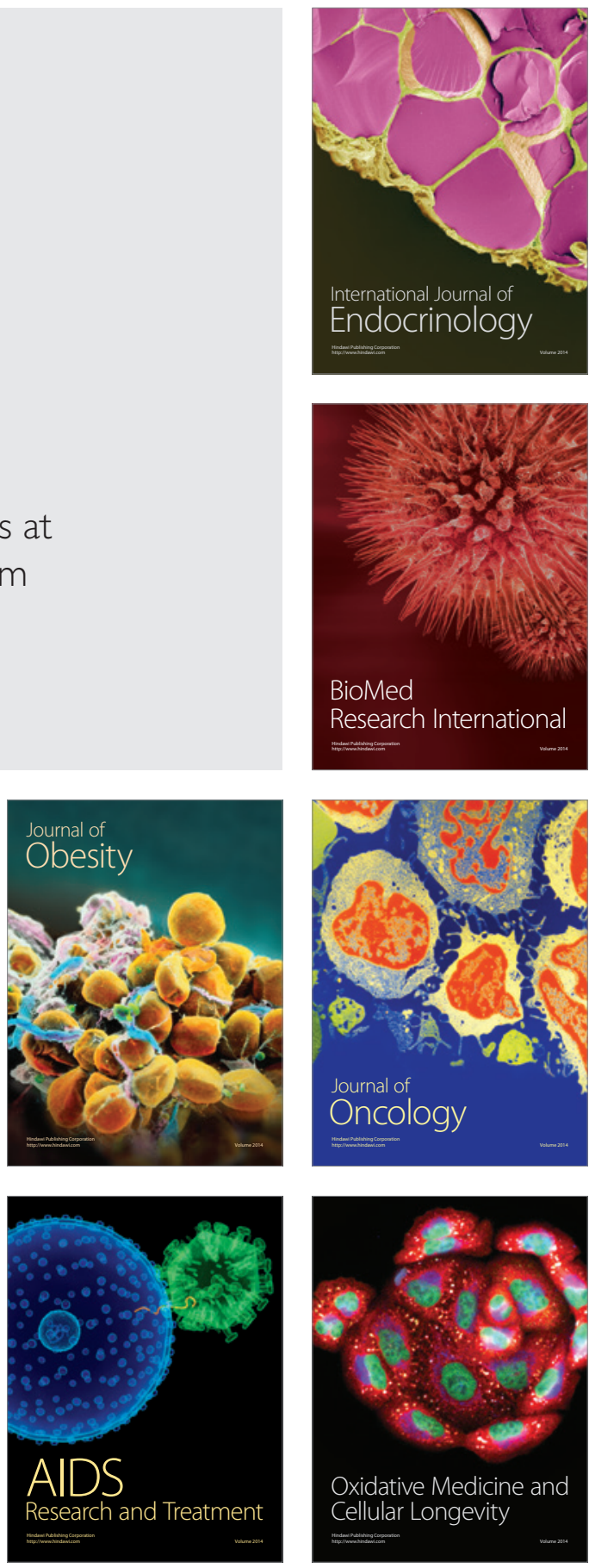